\title{
A case report of anesthesia management in the liver transplantation recipient with porphyria -A case report-
}

\author{
Hye Won Song, Young Hee Shin, Justin Sangwook Ko, Mi Sook Gwak, and Gaab Soo Kim \\ Department of Anesthesiology and Pain Medicine, Samsung Medical Center, Sungkyunkwan University School of Medicine, Seoul, Korea
}

Porphyrias are a group of diseases characterized by an enzyme deficiency in the heme biosynthesis pathway, resulting in accumulation of precursor molecules in the tissue. Some porphyric patients develop progressive liver disease that requires liver transplantation. This case report describes special anesthetic challenges, including careful selection of drugs and the use of special filters that can exclude harmful wavelengths of ultraviolet, in a patient with porphyria who underwent living donor liver transplantation. Understanding the patient's status and disease process, and avoiding triggering factors of porphyria attacks, are important for successful liver transplantation anesthesia in patients with porphyria. (Korean J Anesthesiol 2012; 62: 83-86)

Key Words: Filters, Liver transplantation, Porphyria.

Porphyrias are a group of rare diseases related to an enzyme deficiency in the heme metabolism. In some cases of porphyria, liver transplantation (LT) is considered as the treatment of choice for the life-threatening acute attacks resulting in hepatic failure. Herein, we report a case of a patient with porphyria who underwent LT.

\section{Case Report}

A 23-year-old man (body weight: $60.7 \mathrm{~kg}$, height: $173 \mathrm{~cm}$ ) visited the emergency room with abdominal pain and jaundice, and was admitted for further evaluation. He had been diagnosed with biliary cirrhosis 4 years ago, while being evaluated with abnormal liver function tests after alcohol consumption. Recently, he had visited the emergency room twice with abdominal pain, and was discharged after improving with conservative management.

During his workup, hepatosplenomegaly with collateral vessels was found on abdominal computed tomography, and esophageal varices were found on esophagogastroduodenoscopy. His blood test results were, as follows: total bilirubin, $26.1 \mathrm{mg} /$ dl; direct bilirubin, $16.6 \mathrm{mg} / \mathrm{dl}$; aspartate aminotransferase, 52 $\mathrm{U} / \mathrm{L}$; and alanine aminotransferase, $38 \mathrm{U} / \mathrm{L}$. He had progressing proximal limb pain that could not be controlled by opioids. $\mathrm{He}$ also had skin sensitivity on exposure to sunlight, and there was a family history of multiple skin blisters on exposure to sunlight.

Received: April 22, 2011. Revised: 1st, May 18, 2011; 2nd, June 7, 2011; 3rd, June 8, 2011; 4th, June 9, 2011. Accepted: June 9, 2011.

Corresponding author: Gaab Soo Kim, M.D., Ph.D., Department of Anesthesiology and Pain Medicine, Samsung Medical Center, Sungkyunkwan University School of Medicine, 50, Ilwon-dong, Kangnam-gu, Seoul 135-710, Korea. Tel: 82-2-3410-2470, Fax: 82-2-3410-0361, E-mail: gskim@skku.edu (C) This is an open-access article distributed under the terms of the Creative Commons Attribution Non-Commercial License (http:// creativecommons.org/licenses/by-nc/3.0/), which permits unrestricted non-commercial use, distribution, and reproduction in any medium, provided the original work is properly cited. 
His clinical features were attributed to porphyria, and he was found to have increased coproporphyrin in the stool and uroporphyrin in the urine. During the workup performed to determine the subtype of porphyria, his liver function worsened, and he developed acute liver failure. Also, due to the hypovolemic shock caused by intra-abdominal bleeding, his renal function suddenly deteriorated to the point of needing continuous renal replacement therapy. Therefore, on hospital day 29, he was listed for an emergency LT.

The preoperative electrocardiogram revealed sinus tachycardia, and his echocardiogram was within normal limits. Pulmonary edema and pulmonary effusion were identified on his preoperative chest X-ray. According to the preoperative laboratory data, his model for end-stage liver disease score was 33 points.

He was intubated, and a continuous infusion of norepinephrine $(0.9 \mu \mathrm{g} / \mathrm{kg} / \mathrm{min})$ was given in the intensive care unit (ICU). In the operating room, a Bispectral Index ${ }^{\circledR}$ monitor (Aspect Medical Systems. Inc., Norwood, USA) was attached, and ventilator care was continued at the same ICU settings.

Arterial cannulation was performed with a $20 \mathrm{G}$ catheter in the left radial artery, and central venous cannulation was performed with a 9-Fr Advanced Venous Access catheter (Edwards Lifesciences, Irvine, CA, USA) in the right internal jugular vein. A multifunction Swan-Ganz catheter (Edwards Lifesciences, Irvine, CA, USA) was inserted for hemodynamic monitoring, and the endotracheal tube was changed.

General anesthesia was induced and maintained with total intravenous anesthesia, consisting of $2 \%$ propofol $(100 \mu \mathrm{g} /$ $\mathrm{kg} / \mathrm{min})$ and remifentanil $(0.15 \mu \mathrm{g} / \mathrm{kg} / \mathrm{min})$. The continuous infusion of norepinephrine $(0.9 \mu \mathrm{g} / \mathrm{kg} / \mathrm{min})$ was maintained. The patient had hypovolemic acute renal failure, and atracuronium $(5 \mu \mathrm{g} / \mathrm{kg} / \mathrm{min})$ was infused intravenously. The shadowless surgical lights were covered with special filters (TA-81 filter MAdico Inc., Woburn, USA), and other lights in the operating room were turned off before the patient was brought in.
The LT operation started 75 minutes after induction of anesthesia. Dopamine ( $5 \mu \mathrm{g} / \mathrm{kg} / \mathrm{min}$ ) was added to maintain the mean arterial blood pressure between 60 and $70 \mathrm{mmHg}$, before the anhepatic phase. During the anhepatic period, the hemodynamic profile was stable. Immediately before the reperfusion, $100 \%$ oxygen was given. After reperfusion, the mean blood pressure dropped to about $49 \mathrm{mmHg}$, but it was normalized within 2 minutes, without bolus injections of inotropics. During the operation, the patient was given 10,200 $\mathrm{ml}$ of crystalloid, 1,500 ml of colloid, $670 \mathrm{ml}$ of $5 \%$ albumin, 15 units of packed red blood cells, 4 units of fresh frozen plasma, 6 units of platelet concentrate and 6 units of cryoprecipitate. Calcium gluconate was given intermittently, based on the results of arterial blood gas analyses. He was anuric due to acute renal failure; his total urine output was only $100 \mathrm{ml}$. The patient was transferred back to the ICU after 8 hours and 25 minutes of surgery. Intraoperative laboratory test results are summarized in Table 1.

On the third day after LT, the patient became alert and his renal function improved, so the continuous renal replacement therapy was discontinued. However, his motor function was weak, therefore extubation was delayed.

On the ninth day after LT, his motor power was grade 2 , and examination revealed that he had severe sensory and motor polyneuropathy. He received a tracheostomy on day 13 postLT. The patient's post-LT liver function tests initially improved, but worsened again, and were accompanied by fever about 1 month later. Despite our best efforts to improve his condition, including the administration of antibiotics, he developed multiorgan failure and expired on postoperative day 104.

\section{Discussion}

Porphyrias are a group of either inherited or acquired enzymatic defects of the heme biosynthesis. According to the major site of the abnormal porphyrin production, they are

Table 1. Perioperative Laboratory Values

\begin{tabular}{|c|c|c|c|c|c|c|}
\hline Parameter & PreOP & ICU arrival & POD \# 1 & POD \#2 & POD \#3 & POD \# 10 \\
\hline AST/ALT (U/L) & $9,790 / 1,169$ & $1,362 / 272$ & $586 / 235$ & $410 / 184$ & $321 / 184$ & $113 / 118$ \\
\hline Bilirubin (mg/dl) & 34.2 & 6.9 & 7.1 & 7.1 & 8.4 & 7.1 \\
\hline Gamma-GT (U/L) & 66 & 33 & - & - & 35 & - \\
\hline Albumin (g/dl) & 4.2 & 2.1 & 3.2 & 3.1 & 3.4 & 2.8 \\
\hline BUN (mg/dl) & 26 & 19 & 32.3 & 36.4 & 37.6 & 63 \\
\hline Creatinine (mg/dl) & 1.21 & 1.54 & 1.74 & 1.83 & 1.38 & 1.18 \\
\hline Glucose (mg/dl) & 106 & 126 & 104 & 154 & 106 & 144 \\
\hline PT (INR) & 2.51 & 2.53 & 2.68 & 2.3 & 1.35 & 0.97 \\
\hline Fibrinogen (mg/dl) & 184 & 85 & 141 & 167 & 203 & 179 \\
\hline Hemoglobin (g/dl) & 5.7 & 9.6 & 6.5 & 7.4 & 8.6 & 7.5 \\
\hline
\end{tabular}

AST: aspartate aminotansferase, ALT: alanine aminotransferase, Gamma-GT: gamma-glutamyl transferase, BUN: Blood urea nitrogen, PT: prothromnin time, INR: international normalized ratio, PreOP: preoperative, ICU: intensive care uint, POD: postoperative day. 
classified into hepatic and erythropoietic porphyrias. Each type of porphyria has a characteristic pattern of overproduction and accumulation of heme precursors, based on the location of the dysfunctional enzyme in the heme synthesis pathway. The hepatic porphyrias include acute intermittent porphyria, hereditary coproporphyria, variegate porphyria, aminolevulinic acid dehydratase deficiency porphyria and porphyria cutanea tarda. The erythropoietic porphyrias include uroporphyria and protoporphyria.

Erythropoietic porphyrias are associated with photosensitivity, but are not associated with neuropathy or drug-precipitated crises. Except for porphyria cutanea tarda, hepatic porphyrias are associated with central, peripheral or autonomic neuropathy, mental changes, abdominal pain, and crises frequently precipitated by triggering factors. Infection, dehydration, fever, fasting, psychological stress, physiologic hormonal variation, excessive alcohol intake and the use of porphyrinogenic drugs, such as barbiturates, have been implicated as causes of the acute hepatic porphyria crisis. The signs and symptoms of acute porphyric crisis are severe abdominal pain, vomiting, anxiety, confusion, autonomic instability manifested by hypertension and tachycardia, dehydration, and electrolyte disturbances, such as hyponatremia, hypokalemia and hypocalcemia.

The management of acute porphyria includes symptomspecific treatment for the presenting illness and the use of heme arginate, which reduces the aminolevulinic acid synthase activity and heme production. Hydration and carbohydrate intake may also be considered as supplementary treatment options [1].

There were several anesthetic considerations for this patient because many anesthetics are metabolized by the P45cytochromes and may cause acute attacks of porphyria. From this perspective, drugs have been classified as "safe", "unsafe", or "use with caution" [2]. We chose propofol to induce and maintain anesthesia because its safety has been frequently reported [3-5]. Furthermore, a case of successful LT for the treatment of variegate porphyria was reported, using propofol as the anaesthesia induction and maintenance drug [6]. Opioid analgesics have been used without problems in porphyric patients, and the successful use of remifentanil was recently reported [7]. One study identified the porphyrinogenic effects of atracuronium [8], but another report indicated that this effect was not seen in clinical practice [9]. The vasopressors (i.e. dopamine and norepinephrine) administered during the operation have not been reported as triggers of acute porphyria attacks [10].

Our patient had photosensitivity. In some subtypes of porphyria patients undergoing LT, phototoxic injury to abdominal organs can cause multiple small bowel perforations, which result in uncontrolled sepsis and death [11]. Therefore, we used one of the filters recommended for excluding the most harmful wavelengths from surgical luminaries. luminaires. Since the blue range of the ultraviolet spectrum has been responsible for phototoxicity, we covered the shadowless surgical lights with filters, and the other lights in the room were turned off, as previously reported $[12,13]$. The cell saver was not used because we were unable to find any reports of cell saver use in porphyria cases undergoing LT, and the porphyric subtype was not confirmed before surgery.

After the LT, the patient's liver function improved, but the neuropathy remained. Neurological disorders in porphyria can lead to respiratory paralysis and death. If there is improvement in neuropathy, the functional recovery may be complete, but tends to take a very long time [14]. Therefore, this patient received a tracheostomy.

Gene linkage analysis was planned after ICU discharge in order to determine the porphyria subtype, but this analysis was not performed because the patient's condition deteriorated after about 1 month. We were unable to confirm his porphyric subtype, and presumed that it was variegate porphyria, a congenital erythropoietic porphyria, likely responsible for his symptoms and some of the test results.

Postoperative verification of the porphyrin levels in the urine is a good indicator of improvement, but it was inconvenient in this case, because the test is only carried out twice a month at the Red Cross Center in Korea.

This case shows that LT for the treatment of porphyria can be performed successfully through close monitoring, minimizing perioperative stress, carefully selecting drugs that are safe for porphyria patients and effective filters. Although most anesthetic agents have been used in porphyria patients without problems, caution is necessary.

In conclusion, understanding the patient's status and the disease process and avoiding the triggering factors, based on knowledge of the porphyria attacks, are important for successful LT anesthesia in porphyria patients.

\section{References}

1. Jensen NF, Fiddler DS, Striepe V. Anesthetic considerations in porphyrias. Anesth Analg 1995; 80: 591-9.

2. James MF, Hift RJ. Porphyrias. Br J Anaesth 2000; 85: 143-53.

3. Tidmarsh MD. Porphyria, propofol and rats. Br J Anaesth 1996; 76: 171-2.

4. Sarantopoulos CD, Bratanow NC, Stowe DF, Kampine JP. Uneventful propofol anesthesia in a patient with coexisting hereditary coproporphyria and hereditary angioneurotic edema. Anesthesiology 2000; 92: 607-9.

5. Asirvatham SJ, Johnson TW, Oberoi MP, Jackman WM. Prolonged loss of consciousness and elevated porphyrins following propofol administration. Anesthesiology 1998; 89: 1029-31. 
6. Stojeba N, Meyer C, Jeanpierre C, Perrot F, Hirth C, Pottecher T, et al. Recovery from a variegate porphyria by a liver transplantation. Liver Transpl 2004; 10: 935-8.

7. Durmus M, Turkoz A, Togal T, Koroglu A, Toprak HI, Ersoy MO. Remifentanil and acute intermittent porphyria. Eur J Anaesthesiol 2002; 19: 839-40.

8. Böhrer H, Schmidt H, Bach A, Martin E, Kohl B, Bolsen K, et al. Porphyrinogenic effects of atracurium, vecuronium and pancuronium in a primed rat model. Lab Anim Sci 1994; 44: 326-30.

9. Sneyd JR, Kreimer-Birnbaum M, Lust MR, Heflin J. Use of sufentanil and atracurium anesthesia in a patient with acute porphyria undergoing coronary artery bypass surgery. J Cardiothorac Vasc Anesth 1995; 9: 75-8.
10. Moore MR, Hift RJ. Drugs in the acute porphyrias-toxicogenetic diseases. Cell Mol Biol (Noisy-le-grand) 1997; 43: 89-94.

11. McGuire BM, Bonkovsky HL, Carithers RL Jr, Chung RT, Goldstein LI, Lake JR, et al. Liver transplantation for erythropoietic protoporphyria liver disease. Liver Transpl 2005; 11: 1590-6.

12. Asokumar B, Kierney C, James TW, Amato J, Tumanmd KJ. Anaesthetic management of a patient with erythropoietic protoporphyria for ventricular septal defect closure. Paediatr Anaesth 1999; 9: 356-8.

13. Wahlin S, Srikanthan N, Hamre B, Harper P, Brun A. Protection from phototoxic injury during surgery and endoscopy in erythropoietic protoporphyria. Liver Transpl 2008; 14: 1340-6.

14. Rigal JC, Blanloeil Y. Anaesthesia and porphyria. Minerva Anestesiol 2002; 68: 326-31. 